Revista de Economia Política, vol. 25, no 4 (100), pp. 370-390 outubro-dezembro/2005

\title{
M ercosul: o dilema entre união aduaneira e área de livre-comércio
}

HONORIO KUME GUIDA PIANI*

M ercosur: the dilemma between the customs union and a free trade area. In 2001, the government of A rgentina - facing a major economic crisis - took a rather controversial decision and reduced the tariff rates of all capital goods to zero. This became a main source of conflict with Brazil, the only country of M ercosur that produces such goods. This paper discusses two possible scenarios for the resolution of this issue. In the first one, the countries would opt for the maintenance of the customs union. The authors present some suggestions for the rebuilding of the Common External Tariff (CET), by which the countries would take a middle course acceptable to all. The other possible outcome would be a step back in the direction of a free trade area, with no CET at all.

Key-words: M ercosur; Regional Integration; Tariff.

JEL Classification: F13, F15.

\section{INTRODUÇÃO}

O MERCOSUL foi precedido pelo Programa de Integração e Cooperação Econômica entre a Argentina e o Brasil (PICE), lançado em jul ho de 1986, que visava integrar de forma gradual as duas maiores economias da América do Sul. Em novembro de 1988, o processo foi acelerado com a assinatura do Tratado de Integração, Cooperação e Desenvolvimento, que estabel ecia um prazo máximo de dez anos para se atingir uma zona de livre-comércio, a harmonização gradual das políticas setoriais e a coordenação das políticas macroeconômicas.

\footnotetext{
* Da Diretoria de Estudos M acroeconômicos do Instituto de Pesquisa Econômica Aplicada DIM AC/IPEA. E-mails: kume@ipea.gov.br e guidapiani@ipea.gov.br, respectivamente. O s autores agradecem os comentários de dois pareceristas anônimos. Submetido: julho 2004; aceito: abril 2005.
} 
A posse dos presidentes Collor, no Brasil, e M enen, na A rgentina, e a opção por um regime comercial relativamente mais aberto afetaram radicalmente o processo de integração econômica em curso. Em julho de 1990, a A ta de Buenos Aires reduziu o prazo para a eliminação das tarifas de importação entre os dois países para quatro anos e o objetivo passou a ser o mercado comum, que corresponde a um estágio superior à zona de livre-comércio, com a circulação sem restrições de bens, serviços e fatores produtivos, política comercial uniforme com tarifa externa comum, coordenação de políticas macroeconômicas e harmonização de políticas tributária, agrícola e industrial. N o período de transição, de março de 1991 a dezembro de 1994, as tarifas aduaneiras entre os dois países seriam reduzidas de forma linear e automática a cada semestre (à exceção de uma lista reduzida de produtos). Posteriormente, o Tratado de A ssunção, firmado em março de 1991, incorporou o Paraguai e o U ruguai, países fortemente dependentes do comércio regional com a Argentina e o Brasil.

O M ER COSUL, após cumprida a fase de transição no período 1991/94, entrou em vigor em 1995, com uma tarifa externa comum (TEC) cuja plena vigência está prevista para 2006. N o entanto, os países-membros têm, por vezes, tomado iniciativas que "perfuram" a TEC, baseados em argumentos macroeconômicos. Para tal, têm buscado a aprovação de seus parceiros, os quais quase invariavelmente acabam por referendar as demandas por aquelas medidas. Entretanto, os custos dessa proteção adicional têm sido, em geral, assumidos pelo país interessado, permitindo evitar conflitos regionais em razão dessas medidas, que flexibilizam a rigidez na aplicação da TEC imposta pela união aduaneira.

A partir de 2001, as alterações nas tarifas promovidas pelo governo argentino, principalmente sobre bens de capital, seguidas pelo governo uruguaio, têm provocado discussões sobre uma eventual reforma tarifária no M ERCOSUL ou, até mesmo, a substituição da união aduaneira atual por uma zona de livre-comércio, o que permitiria a cada país-membro autonomia na condução de sua política comercial.

Este trabalho tem dois objetivos: primeiro, supondo a manutenção da união aduaneira, apresentar sugestões para uma reestruturação da TEC, tornando-a mais apropriada ao estímulo da competitividade externa e ao crescimento econômico e, segundo, discutir os interesses conflitantes entre os parceiros do M ERCOSUL, no caso de um retrocesso em direção a uma área de livre-comércio.

A lém desta breve introdução, este estudo está dividido em quatro seções. $\mathrm{Na}$ Seção 2, serão mostrados os indicadores econômicos básicos dos países-membros do M ERCOSUL e o desempenho do comércio intra-regional recente. $\mathrm{N}$ a Seção 3 , serão descritas e analisadas as estruturas das tarifas nominal e efetiva, por setor de atividade, no M ER COSUL. D estaque é dado à discussão sobre o nível tarifário de bens de capital, um dos pontos mais controversos, o que permitirá a apresentação de propostas para uma reforma tarifária no M ER COSUL. N a Seção 4, após um resumo das principais modificações introduzidas na TEC por cada país-membro até a ocorrência das divergências mais radicais sobre as tarifas de bens de capital, será discutido o dilema entre a manutenção da união adua- 
neira, com eventuais modificações na TEC, ou o retrocesso a uma zona de livrecomércio, o que permitiria aos países-membros plena autonomia na condução da política comercial. Finalmente, na Seção 5, serão resumidos os principais resultados e apresentadas recomendações para a política comercial do bloco.

\section{MERCOSUL: PANORAMA GERAL}

Em 2002, o M ER COSUL constituía um mercado regional importante, com um PIB de US $\$ 673,8$ bilhões, uma população de 219,8 milhões de habitantes e uma renda percapita de aproximadamente US\$3.065. A participação dos fluxos de comércio (exportações e importações) no PIB atingiu $26,8 \%$ e, na composição do PIB, a agricultura alcançou 7,3\% , a indústria $23,5 \%$ e os serviços $69,2 \%$ (Tabela 1).

Tabela 1

Indicadores econômicos do MERCOSUL - 2002

\begin{tabular}{lcrrrc}
\hline Descrição & Argentina & Brasil & Paraguai & Uruguai & MERCOSUL \\
\hline 1. PIB (US\$ milhões) & 153,9 & 498,7 & 6,5 & 14,7 & 673,8 \\
2.Composição do PIB (\%) & & & & & \\
2.1 Agricultura & 10,8 & 8,2 & 22,0 & 9,4 & 9,0 \\
2.2 Indústria & 32,4 & 36,1 & 28,4 & 26,8 & 34,8 \\
2.3 Serviços & 56,8 & 55,7 & 49,6 & 63,8 & 56,2 \\
3. Renda percapita (US\$) & 4.216 & 2.860 & 1.182 & 4.324 & 3.065 \\
4. População (milhões de pessoas) & 36,5 & 174,4 & 5,5 & 3,4 & 219,8 \\
5. Comércio/PIB (\%) & 33,6 & 24,3 & 50,8 & 31,5 & 26,8 \\
\hline
\end{tabular}

Fonte: Dados brutos: World Development Indicators - Data Query e IBGE (composição do PIB). Elaboração própria

As economias dos países-membros, no entanto, são bastante diferenciadas - os PIBs dos dois maiores países, Brasil e Argentina, respectivamente, de US\$ 498,7 bilhões e US\$153,9 bilhões, são muito superiores aos do Uruguai (US\$ 14,7 bilhões) e do Paraguai (US\$ 6,5 bilhões). Quanto a suas estruturas produtivas, apenas Argentina e Brasil apresentam fortes semelhanças. 0 Brasil tem a indústria mais importante e o Paraguai é o mais dependente da agricultura. O s níveis de renda per capita também apresentam grandes disparidades, sendo os mais elevados na Argentina e no Uruguai.

A despeito das grandes diferenças de magnitude e de composição setorial de suas economias, os quatro países do bloco têm enfrentado situações de desequilíbrios macroeconômicos similares nos últimos anos. Em particular, A rgentina e Brasil protagonizaram crises inflacionárias ${ }^{1}$ durante a década de 1980, que só foram contornadas com a implementação de programas de estabilização macroe-

\footnotetext{
${ }^{1}$ Em 1989, a taxa de inflação anual atingiu 4.883\% na Argentina e $1.878 \%$ no Brasil.
} 
conômica, baseados em âncoras cambiais nos anos 1990 - regimes de taxa de câmbio fixa ou administrada - que se, de um lado, reduziram substancialmente as taxas de inflação, por outro produziram déficits em conta-corrente que se mostraram insustentáveis no longo-prazo.

O Plano de Conversibilidade argentino, apoiado na paridade cambial fixa de um peso por um dólar, teve início em abril de 1991, o que resultou, nos primeiros quatro anos, em uma rápida queda das taxas de inflação e em forte crescimento econômico. Entretanto, os déficits crescentes, tanto nas contas públicas como nas contas externas, requeriam um financiamento externo cuja disponibilidade de recursos dependia das condições vigentes no mercado financeiro internacional. As crises asiática e russa verificadas após 1997 e as dúvidas sobre a capacidade de a A rgentina honrar as dívidas acumuladas reduziram tal financiamento, levando a economia a entrar em recessão (Tabela 2).

Tabela 2

Indicadores macroeconômicos escolhidos do MERCOSUL

\begin{tabular}{lrrrrrr}
\hline \multicolumn{1}{c}{ País } & 1997 & 1998 & 1999 & 2000 & 2001 & 2002 \\
\hline $\begin{array}{l}\text { 1. Variação do PIB (\%) } \\
\text { Argentina }\end{array}$ & 8,1 & 3,9 & $-3,4$ & $-0,8$ & $-4,4$ & $-10,9$ \\
Brasil & 3,3 & 0,1 & 0,8 & 4,4 & 1,4 & 1,5 \\
Paraguai & 2,6 & $-0,4$ & 0,5 & $-0,4$ & 2,7 & $-3,9$ \\
Uruguai & 5,1 & 4,5 & $-3,2$ & 1,1 & $-3,1$ & $-10,8$ \\
2. Inflação - IPC ${ }^{1}$ (\%) & & & & & & \\
Argentina & 0,5 & 0,9 & $-1,2$ & $-0,9$ & $-1,1$ & 25,9 \\
Brasil & 6,0 & 3,8 & 4,8 & 6,2 & 7,5 & 10,2 \\
Paraguai & 7,0 & 11,6 & 6,8 & 9,0 & 7,3 & 10,5 \\
Uruguai & 19,8 & 10,8 & 5,7 & 4,8 & 4,4 & 14,4 \\
3. Taxa de câmbio nominal & & & & & & \\
Argentina (peso/US\$) & 1,00 & 1,00 & 1,00 & 1,00 & 1,00 & 3,09 \\
Brasil (real/US\$) & 1,08 & 1,16 & 1,81 & 1,83 & 2,35 & 2,93 \\
Paraguai (guarani/US\$) & $2.191,0$ & $2.755,7$ & $3.117,5$ & $3.470,6$ & $4.116,8$ & $5.747,3$ \\
Uruguai (peso/US\$) & 9,4 & 10,8 & 11,3 & 12,0 & 13,3 & 21,0 \\
\hline
\end{tabular}

1/ Variação anual média. 2/ Taxa de câmbio nominal média do ano.

Fonte: Centro de Economia Internacional do Ministerio das Relaciones Exteriores, Comercio Intemacional y Culto da Argentina.

Em 2002, a desvalorização do peso, que atingiu, em média, 3,1 pesos por dólar, associada ao congelamento dos depósitos bancários e à insolvência generalizada, gerou uma queda no PIB argentino de 10,9\%.

Em julho de 1994, o Brasil implementou um programa de estabilização de preços - o Plano R eal - , baseado em uma taxa de câmbio administrada, obtendo também uma rápida queda nas taxas de inflação, mas com déficits crescentes em transações correntes financiados por recursos externos. A crise finan- 
ceira internacional no final dos anos 1990 e a suspeita de que o Brasil não conseguiria manter a taxa de câmbio sob controle aceleraram a fuga de capitais, provocando a mudança no regime cambial, em 1999, com a adoção de uma taxa de câmbio flexível, evitando uma grave crise no balanço de pagamentos. A substituição da âncora cambial pelo regime de metas de inflação, como referência para as variações nos preços nominais, foi um dos fatores que impediram uma explosão inflacionária. No entanto, após um crescimento do PIB de 4,4\%, em 2000, a economia brasileira não conseguiu manter uma trajetória de crescimento econômico sustentável.

Os países de economias relativamente pequenas do M ER COSUL, Paraguai e Uruguai, sofreram impactos negativos derivados das crises dos países vizinhos, sobretudo em suas taxas de crescimento econômico e na desvalorização das suas moedas.

A evolução do comércio exterior total (exportação e importação) do M ER COSUL foi bastante positiva, passando de US\$73,8 bilhões, em 1990, para US\$ 148,2 bilhões, em 2002, o que corresponde a uma variação de pouco mais de $100 \%$. 0 crescimento do comércio intra-regional foi de 148,8\%, enquanto o comércio extra-regional teve um incremento de 94,8\% (Tabela 3).

Tabela 3

Fluxo anual de comércio intra e extra-MERCOSUL (em US\$ bilhões)

\begin{tabular}{lrrrrrrrr}
\hline Fluxo anual & 1990 & 1994 & 1998 & 2002 & $\begin{array}{r}(\Delta \%) \\
94 / 90\end{array}$ & $\begin{array}{r}(\Delta \%) \\
98 / 94\end{array}$ & $\begin{array}{r}(\Delta \%) \\
02 / 98\end{array}$ & $\begin{array}{r}(\Delta \%) \\
02 / 00\end{array}$ \\
\hline 1. Intra-MERCOSUL & 8,2 & 23,7 & 40,8 & 20,4 & 188,7 & 71,8 & $-50,0$ & 148,8 \\
1.1 Argentina-Brasil & 4,2 & 15,8 & 29,8 & 14,3 & 277,2 & 88,8 & $-52,0$ & 240,5 \\
1.2 Outros & 4,0 & 8,0 & 11,0 & 6,1 & 97,2 & 38,3 & $-44,5$ & 52,5 \\
2. Extra-MERCOSUL & 65,6 & 98,2 & 135,8 & 127,8 & 49,7 & 38,9 & $-5,9$ & 94,8 \\
3.Total & 73,8 & 121,9 & 177,6 & 148,2 & 65,2 & 45,3 & $-16,6$ & 100,8 \\
\hline
\end{tabular}

Fonte: Centro de Economia Internacional, Ministerio de Relaciones Exteriores, Comercio Internacional y Culto da Argentina. Elaboração própria.

Pode-se notar que a expansão de comércio foi bastante diferenciada nos três subperíodos: 1990/1994 abrange a fase de transição do M ER CO SUL, ao longo do qual as tarifas incidentes sobre as importações dos países-membros foram reduzidas de forma gradual e linear no início de cada semestre e ao mesmo tempo em que os países implementavam programas unilaterais de liberalização comercial. O subperíodo seguinte - 1994/1998 - corresponde à etapa da união aduaneira imperfeita, quando as tarifas aplicadas aos países sócios haviam sido eliminadas, salvo algumas exceções. 0 terceiro e último - 1998/2002 - reflete uma fase de baixa atividade econômica na região, associada a fortes atritos comerciais entre os países do bloco.

No período 1990/1994, o comércio intra-M ER COSUL apresentou um cres- 
cimento extraordinário, de $188,7 \%$, comparado ao aumento do comércio com o resto do mundo, de quase $50 \%$. A evolução do comércio intra-regional não foi uniforme entre os quatro países, sendo a maior parcela apropriada pela A rgentina e pelo Brasil, cujas trocas comerciais passaram de US\$ 4,2 bilhões para US\$ 15,8 bilhões - um acréscimo que corresponde a quase 75\% da variação absoluta observada no comércio intra-regional.

N o período 1994/1998, embora menos acentuada, a expansão do comércio intra-regional continuou predominante, aumentando $71,8 \%$, contra $38,9 \%$ do comércio extra-regional.

N o período 1998/2002, ocorreu um forte retrocesso no comércio intra-regional, passando de US $\$ 40,8$ bilhões para US $\$ 20,4$ bilhões, com queda de $50 \%$. 0 comércio extra-regional apresentou uma pequena redução de 5,9\% .

O inequívoco sucesso observado no período 1990/1998 pode ser explicado por outros fatores, além dos relacionados às preferências regionais, como, por exemplo, a competitividade artificial decorrente da falta de coordenação das políticas macroeconômicas, principalmente na área cambial, bem como pelo crescimento econômico vigoroso permitido pelo êxito inicial dos programas de estabilização, especialmente na Argentina e no Brasil.

Como pode ser observado na Tabela 4, a parcela das exportações destinadas ao M ER CO SUL no total de cada país-sócio aumentou de forma generalizada, sobretudo no caso do Brasil, que passou de 4,2\%, em 1990, para 17,4\%, em 19982. Este resultado pode ser explicado, em parte, pelas menores preferências tarifárias que os demais membros do M ER COSUL concediam ao Brasil nos acordos bilaterais firmados anteriormente.

Tabela 4

Participação das exportações e das importações com o MERCOSUL no total (em \%)

\begin{tabular}{lrrrrrrrr}
\hline \multicolumn{9}{c}{ Exportação } \\
\hline País & 1990 & 1994 & 1998 & 2002 & 1990 & 1994 & 1998 & 2002 \\
Argentina & 14,8 & 30,3 & 35,6 & 21,7 & 20,4 & 22,2 & 25,3 & 32,3 \\
Brasil & 4,2 & 13,6 & 17,4 & 5,5 & 11,2 & 13,8 & 16,3 & 14,9 \\
Paraguai & 39,5 & 46,2 & 51,7 & 58,1 & 30,0 & 45,8 & 62,1 & 55,6 \\
Uruguai & 34,8 & 47,0 & 55,4 & 32,8 & 39,9 & 48,9 & 43,3 & 48,1 \\
\hline
\end{tabular}

Fonte: Centro de Economia Internacional, Ministerio de Relaciones Exteriores, Comercio Internacional y Culto da Argentina.

Verifica-se, igualmente, uma expansão importante na participação das importações provenientes de membros do M ERCOSUL, sendo a mais substancial a do Paraguai, alcançando 62,1\% de suas compras externas em 1998.

Em comparação com outros blocos, porém, a participação do comércio in-

${ }^{2}$ A comparação com 2002 foi evitada, tendo em vista a forte recessão econômica nos países do M ER COSUL, principalmente na Argentina e no Uruguai. 
tra-regional no comércio total do M ER COSUL, que alcançou 20,8\%, em 2001, não viabilizou patamares semelhantes aos obtidos, por exemplo, pela União Européia $(61,2 \%)$ e N AFTA $(54,8 \%)$, ainda que seja próxima da ASEAN $(22,4 \%)$

- associação composta por Brunei, Camboja, Cingapura, Filipinas, Indonésia, Laos, M alásia, Tailândia e Vietnã - e tenha superado a Comunidade A ndina $\left(11,2 \%\right.$ ) e o A cordo Austrália e N ova Z elândia (9,7\% ), naquele mesmo ano ${ }^{3}$.

Em resumo, apesar do excelente desempenho do comércio intra-regional, não é surpreendente que, dadas as assimetrias entre os países-membros e as dificuldades enfrentadas em virtude dos programas de estabilização econômica, ocorressem, periodicamente, conflitos comerciais. Freqüentemente, as disputas resultaram em demandas por aumento de proteção setorial e em mudanças na tarifa externa comum, enfatizando-se os custos sociais de curtoprazo em detrimento dos benefícios de longoprazo.

\section{A ESTRUTURA TARIFÁRIA NO MERCOSUL}

\subsection{D escrição da tarifa externa comum}

A tarifa externa comum (TEC) aprovada para o M ER COSUL apresentava uma média de $12 \%$, uma amplitude de zero a $20 \%$ e alíquotas crescentes em dois pontos de percentagem, de acordo com o grau de elaboração ao longo da cadeia produtiva. Assim, as alíquotas dos insumos variavam entre $0 \%$ e $12 \%$, as de bens de capital de $12 \%$ a $16 \%$ e as de bens de consumo de $18 \%$ a $20 \%$.

A princípio, duas críticas poderiam ser feitas a essa estrutura tarifária: a primeira, ao número excessivo de alíquotas, em detrimento de uma simplicidade maior na administração aduaneira, e a segunda, à falta de uniformidade da proteção efetiva, pois privilegiou-se a escalada na tarifa nominal, com o objetivo de assegurar uma proteção efetiva crescente em cada etapa da estrutura produtiva. Entretanto, um número grande de alíquotas permitiu acomodar mais facilmente os interesses dos quatro países, enquanto a escalada da tarifa nominal reproduziu o dogma predominante de que as proteções efetivas de bens finais devem ser superiores às de bens intermediários e às de bens de capital (Kume, 1996). Embora não tenha respaldo teórico (Corden, 1971 e Johnson, 1964), este tipo de estrutura tarifária é o predominante na maioria dos países.

Uma solução para os produtos que geravam maior controvérsia, em decorrência de interesses nacionais muito distantes, foi aceitar temporariamente tarifas diferenciadas, de modo que o ônus de uma tarifa maior fosse assumido apenas pelo próprio país. Assim, a TEC permitiu exceções para dois grupos de

\footnotetext{
${ }^{3}$ O s dados de participação do comércio intra-regional sobre o comércio total foram obtidos da O M C (2003). Vale lembrar que essa medida é sensível à dimensão do bloco regional e ao número de membros, devendo ser considerada apenas como um dos indicadores da importância do comércio intrabloco.
} 
produtos: o primeiro, composto de bens de capital (900 itens tarifários) e produtos de informática e telecomunicações (200 itens tarifários), no qual as tarifas nacionais eram bastante distintas, gerando um processo de negociação específico, e o segundo grupo, denominado Lista de Exceção $\mathrm{N}$ acional, abrangendo os produtos para os quais cada país considerava inapropriada uma mudança repentina na tarifa nacional, por motivos protecionistas ou para evitar um impacto abrupto sobre os custos de produção ou investimento.

Para o setor de bens de capital, cuja produção é geograficamente muito concentrada no Brasil, a tarifa externa modal foi fixada em $14 \%$, inferior em seis pontos de percentagem à tarifa modal brasileira para o setor, mas bastante superior às efetivamente pagas nos países sócios (as tarifas nacionais são atenuadas por isenções proporcionadas por regimes especiais de importação). Para os produtos de informática e telecomunicações, a tarifa externa foi estabelecida em $16 \%$, contra tarifas de $35 \%$ e $40 \%$, respectivamente, no Brasil, que é o único produtor regional. Para evitar que o custo do desvio de comércio - provocado pela substituição das importações do resto do mundo por compras a preços mais elevados provenientes do Brasil - fosse assumido instantaneamente pelos sócios importadores, fixou-se um programa de convergência linear, encerrado no final de 2001, para bens de capital, e que deverá terminar em 2006, para os bens de informática e telecomunicações.

Para a elaboração do segundo grupo, cada país selecionou produtos cujas alíquotas convergiam linearmente à tarifa externa comum no prazo de cinco anos. A quota de bens para a A rgentina foi idêntica à do Brasil, de 300 itens tarifários, enquanto o Paraguai e o Uruguai puderam incluir 399 produtos cada um.

Para a indústria automobilística, os regimes nacionais existentes foram mantidos com pequenas adaptações, através da concessão de tratamento nacional para os produtos similares produzidos na região e de uma preferência maior aos produtores regionais de autopeças. $\mathrm{N}$ a realidade, apesar das concessões realizadas pela A rgentina, o seu regime automotriz manteve as restrições ao livre fluxo de automóveis e autopeças no M ER CO SUL. A té 2000 deveria ter sido aprovado um novo regime automotriz para o M ER COSUL, o que foi alcançado somente no início de 2001, tendo a aprovação formal sido suspensa em decorrência dos conflitos comerciais entre A rgentina e Brasil.

$\mathrm{N}$ a Tabela 5 são apresentadas as estimativas de tarifas nominal e efetiva por setor de atividade.

A tarifa externa comum nominal no M ER COSUL apresenta uma média simples de $12,4 \%$ e um desvio-padrão, indicador do grau de uniformidade da estrutura tarifária, de $5,9 \%$. O s cinco setores mais protegidos são automóveis, caminhões e ônibus $(34 \%)$; vestuário $(19,6 \%)$; plástico $(16,5 \%)$; têxtil $(16,4 \%)$; material elétrico (16\%); e outros produtos metalúrgicos (15,8\%).

A tarifa efetiva, definida como o incremento no valor adicionado proporcionado pela estrutura tarifária em relação ao valor adicionado de livre-comércio, ${ }^{5}$ 
Tabela 5

Tarifa externa comum do MERCOSUL prevista para 2006, nominal e efetiva por setor de atividade

\begin{tabular}{|c|c|c|c|}
\hline Códig & Atividade & Nominal (\%) & Efetiva (\%) \\
\hline 1 & Agropecuária & 3,8 & 2,9 \\
\hline 2 & Extrativa Mineral (exceto combustíveis) & 3,9 & 1,7 \\
\hline 3 & Petróleo e Carvão & 0,0 & $-1,8$ \\
\hline 4 & Produtos Minerais Metálicos & 11,5 & 13,3 \\
\hline 5 & Siderurgia & 8,0 & 12,5 \\
\hline 6 & Metalurgia dos Não-ferrosos & 10,0 & 10,3 \\
\hline 4 & Outros Produtos Metalúrgicos & 15,8 & 21,2 \\
\hline 8 & Máquinas e Tratores & 13,8 & 14,2 \\
\hline 10 & Material Elétrico & 16,0 & 20,0 \\
\hline 11 & Equipamentos Eletrônicos & 13,1 & 12,9 \\
\hline 12 & Automóveis, Caminhões e Ônibus & 34,0 & 124,0 \\
\hline 13 & Outros Veículos e Peças & 13,8 & 14,2 \\
\hline 14 & Madeira e Mobiliário & 11,0 & 13,1 \\
\hline 15 & Celulose, Papel e Gráfica & 11,9 & 12,7 \\
\hline 16 & Borracha & 12,8 & 14,7 \\
\hline 17 & Fabricação de Elementos Químicos & 12,8 & 13,9 \\
\hline 18 & Refino de Petróleo & 4,6 & 5,3 \\
\hline 19 & Produtos Químicos Diversos & 8,8 & 10,6 \\
\hline 20 & Farmacêutica e Perfumaria & 10,0 & 9,9 \\
\hline 21 & Artigos de Plástico & 16,5 & 20,6 \\
\hline 22 & Têxtil & 16,4 & 21,8 \\
\hline 23 & Vestuário & 19,6 & 22,3 \\
\hline 24 & Couros e Calçados & 14,2 & 15,7 \\
\hline 25 & Indústria do Café & 11,3 & 11,7 \\
\hline 26 & Beneficiamento de Produtos Vegetais & 12,1 & 22,2 \\
\hline 27 & Abate de Animais & 9,8 & 9,8 \\
\hline 28 & Indústria de Laticínios & 15,6 & 16,6 \\
\hline 29 & Açúcar & 16,0 & 16,9 \\
\hline 30 & Fabricação de Óleos Vegetais & 8,7 & 9,9 \\
\hline 31 & Bebidas e outros Produtos Alimentares & 15,7 & 23,6 \\
\hline \multirow[t]{10}{*}{32} & Produtos Diversos & 14,4 & 16,1 \\
\hline & Média Simples & 12,4 & 17,2 \\
\hline & Média Simples, Exceto Automóveis, Ônibus & 11,7 & 13,6 \\
\hline & Mediana & 12,8 & 13,9 \\
\hline & Mediana, Exceto Automóveis, Ônibus & 12,5 & 13,6 \\
\hline & Mínimo & 0,0 & $-1,8$ \\
\hline & Máximo & 34,0 & 124,0 \\
\hline & Máximo, exceto Automóveis, Ônibus & 19,6 & 23,6 \\
\hline & Desvio-padrão & 5,9 & 20,7 \\
\hline & Desvio-padrão, exceto Automóveis, Ônibus & 4,4 & 6,2 \\
\hline
\end{tabular}

Fonte: Dados brutos: Tarifa Externa Comum do Mercosul. Elaboração própria.

\footnotetext{
${ }^{4} \mathrm{~N}$ este setor, estão sendo utilizadas as tarifas negociadas recentemente no acordo automotivo do MERCOSUL, cuja formalização está suspensa conforme explicado anteriormente.

${ }^{5}$ Ver metodologia de cálculo no A nexo.
} 
alcança $17,2 \%$, em média. O s setores mais favorecidos são: automóveis, caminhões e ônibus ( $124 \%$ ); bebidas e outros produtos alimentares $(23,6 \%)$; vestuário $(22,3 \%)$; beneficiamento de produtos vegetais $(22,2 \%)$; e outros produtos metalúrgicos $(21,1 \%)$.

Dada a disparidade no nível de proteção efetiva da indústria automotiva em relação ao de outros setores, os indicadores estatísticos foram recalculados excluindo-se esse setor. A dotando este procedimento, a tarifa nominal média simples cai para $11,7 \%$, com desvio-padrão de $4,4 \%$, e a tarifa efetiva para $13,6 \%$, com desvio-padrão de $6,2 \%$.

\subsection{A tarifa de bens de capital no M ER C O SU L}

A fixação de uma tarifa aduaneira modal de $14 \%$ nas importações de máquinas e equipamentos sempre foi motivo de grande controvérsia, tanto no Brasil como entre os países-membros do M ERCOSUL. De um lado, estavam aqueles que priorizavam o estímulo aos investimentos privados, assim favorecendo as exportações e o crescimento econômico, e, de outro, os que pretendiam evitar que isso fosse viabilizado através da eliminação da produção regional de bens de capital.

A definição de uma tarifa "ideal" para bens de capital deveria permitir a conciliação desses dois objetivos, ou seja, assegurar uma proteção adequada aos produtores regionais sem comprometer substancialmente a competitividade internacional da produção no M ERCOSUL - uma questão de resolução não trivial.

0 argumento em favor da aplicação de uma política tarifária discriminatória contra bens de capital foi fortalecido recentemente pelos estudos de Bradford De Long e Summers (1991) e J ones (1994), que mostraram que diferenças nas taxas de crescimento entre países estão mais associadas ao diferencial no preço relativo de bens de capital do que a diferenças nas taxas de poupança. Em estudo mais recente, $\mathrm{H}$ sieh (2000) mostrou que o preço relativo de bens de capital está associado negativamente à participação das importações no investimento total em máquinas e equipamentos, dificultando o acesso a novas tecnologias.

Eaton e Kortum (2001) resumem as principais características do comércio e da produção de máquinas e equipamentos no mercado internacional:

a) a especialização na produção de máquinas e equipamentos ocorre principalmente em países desenvolvidos; 6

b) entre os países da OCDE, a especialização na produção de máquinas e equipamentos, medida pela participação do valor adicionado dessa atividade sobre o PIB, está fortemente associada aos gastos das empresas em pesquisa e desenvolvimento ( $P \& D)$ como proporção do PIB;

C) as vendas externas de máquinas e equipamentos são dominadas por sete países - Estados Unidos, Japão, A lemanha, R eino Unido, França, Itália e Suécia - , cuja participação nas exportações mundiais daquela indústria atingiu

${ }^{6} \mathrm{~N}$ a amostra de países utilizada por Eaton e Kortum (2001), apenas a Coréia do Sul, a H ungria e a Iugoslávia apresentavam uma produção mais significativa de máquinas e equipamentos. 
$60,4 \%$, em 1997. Este resultado mostra que a produção de máquinas e equipamentos está concentrada em um pequeno número de países e que a difusão de novas tecnologias é feita através do comércio. $\mathrm{N}$ o entanto, a participação desse grupo de países tem declinado gradualmente, desde 1967, quando atingiu 75,7\% uma queda de 15 pontos de percentagem em 31 anos. O utros países - principalmente os asiáticos - vêm ocupando um espaço cada vez maior nesse mercado; e

d) as importações de máquinas e equipamentos são substancialmente menos concentradas, embora a participação dos sete principais importadores mundiais tenha aumentado de $37,4 \%$, em 1967, para $47,2 \%$, em 1997. O s principais países exportadores também são os importadores mais rel evantes, à exceção do Canadá.

Esse diagnóstico sobre a estrutura de produção e comércio de máquinas e equipamentos sinaliza que dificilmente o Brasil chegaria a fazer parte, a curto ou médio prazo, do grupo de países produtores e exportadores de máquinas e equipamentos. A ssim, para o M ER COSUL, o acesso a inovações tecnológicas continuaria dependendo fundamentalmente das importações desses bens.

Segundo J ones (1994), o efeito de eventuais distorções nos preços relativos de bens de capital em relação aos de consumo sobre a taxa de crescimento econômico depende, na maioria das vezes, do contexto em que elas ocorrem. Contudo, seus resultados empíricos, para uma ampla amostra de países, indicam que distorções nos preços relativos de bens de capital, em particular de máquinas e equipamentos, estão associadas a menores taxas de crescimento no período 1960/85. Em estudo anterior, Bradford de Long e Summers (1991) obtêm resultados similares, relacionando taxas de investimento em máquinas e equipamentos a crescimento da renda per capita.

$\mathrm{N}$ a ausência de informações sobre o preço relativo de máquinas e equipamentos no M ERCOSUL, para avaliar se existe uma restrição aos investimentos, a tarifa de máquinas e equipamentos (Seção 16 do Sistema H armonizado) será comparada com a tarifa média de produtos industrializados (Seções 6 a 20), para vários países. ${ }^{7}$ É claro que a comparação de tarifas entre países nunca é precisa, pois os dados disponíveis só registram as alíquotas ad valorem, não sendo computadas as tarifas específicas e as variáveis, bem como os regimes especiais de tributação, que permitem a importação sem pagamento integral dos impostos. N o entanto, como o número de observações sobre o qual é calculada a tarifa média de cada produto é el evado, esses erros e omissões não devem introduzir um viés significativo.

N o M ERCOSUL, a tarifa média fixada para máquinas e equipamentos, em relação à média dos produtos industrializados, atinge $0,96 .^{8}$

0 Gráfico 1 expõe as tarifas relativas de bens de capital para um conjunto de países e blocos econômicos. Pode-se notar que a tarifa relativa de máquinas e

\footnotetext{
${ }^{7}$ As informações sobre tarifas foram obtidas em UN CTAD (2000).

${ }^{8}$ Como a Argentina era o único país do M ER COSUL, em 1999, que aplicava a tarifa plena de bens de capital prevista para 2006, estamos considerando a tarifa relativa de máquinas e equipamentos desse país como aproximadamente equivalente à do M ER COSUL.
} 
equipamentos no M ERCOSUL não é muito diferente daquelas praticadas por outros países em desenvolvimento, tais como C hile, Coréia do Sul e M éxico. No entanto, é bem superior à tarifa relativa aplicada pelos países desenvolvidos e asiáticos. M erece destaque, ainda, a forte discriminação contra a produção de bens de capital verificada em Cingapura e no J apão, este último pertencente ao grupo dos principais países exportadores.

Gráfico 1

Tarifa de máquinas e equipamentos em relação à tarifa de produtos industrializados: países e blocos seecionados

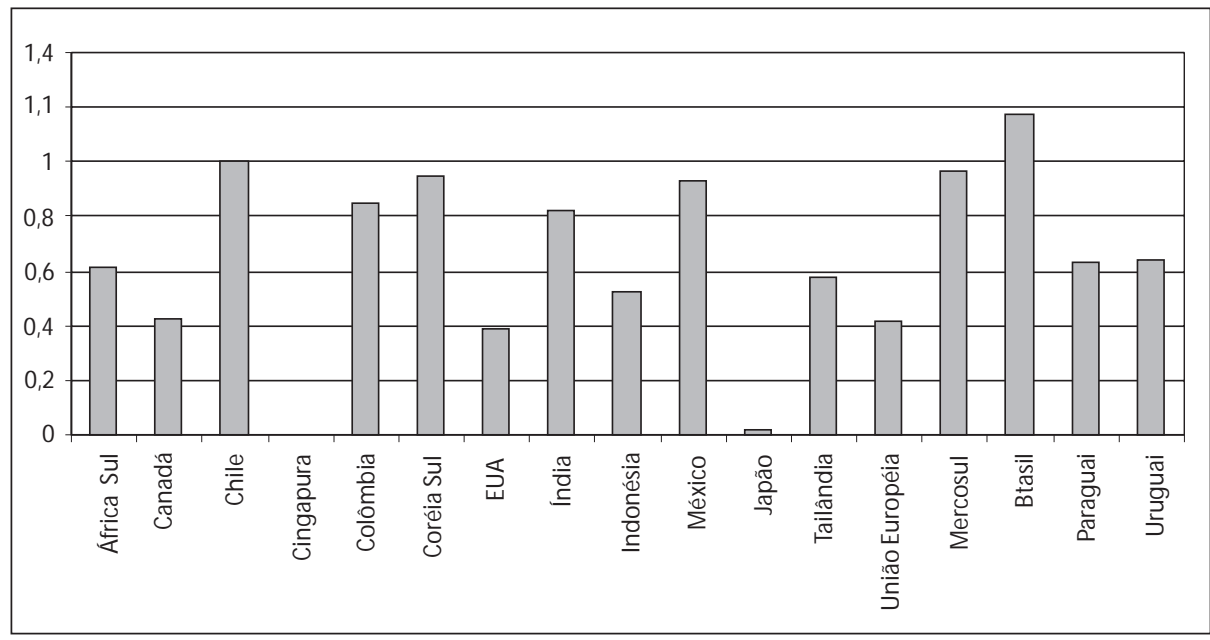

Fonte: UNCTAD, 2000, versão 7.0. Elaboração própria.

Com base nesses resultados, não há elementos para concluir que a tarifa relativa de bens de capital, aprovada para o M ER COSUL, seja nitidamente desfavorável à competição externa ou ao estímulo ao investimento. No caso de se aceitar, porém, que há uma forte correlação entre tarifa relativa e preço relativo de bens de capital, as conclusões de Bradford De Long e Summers (1991) e J ones (1994) indicam que uma redução das tarifas de bens de capital poderia ter efeitos importantes sobre a taxa de crescimento econômico no bloco.

\subsection{R eforma tarifária no M ER C O SU L}

A teoria econômica mostra que uma tarifa nominal uniforme é ótima, na medida em que gera proteções efetivas idênticas para todos os setores, o que resulta em uma alocação eficiente de recursos produtivos. No entanto, sua validade está condicionada às suposições de que as externalidades são nulas, ou, pelo menos, insignificantes, de que inexistem bens exportáveis e de que os efeitos sobre o consumo são desprezíveis (Corden, 1971). Q uando essas hipóteses não são aceitas, a determinação de uma estrutura tarifária ótima torna-se uma tarefa ex- 
tremamente complexa, requerendo um conjunto de dados que usualmente não são disponíveis.

$\mathrm{N}$ a ausência dessas informações, alguns autores, como Corden (1971), ainda recomendam uma tarifa uniforme, indicando duas vantagens adicionais: a) simplifica a administração aduaneira e b) reduz as pressões políticas em favor de determinados segmentos produtivos. Panagariya e R odrik (1991) concluem que possivelmente o regime de tarifa uniforme apresenta um nível de bem-estar maior que um regime de tarifas diferenciadas, pois minimiza o desvio de recursos para atividades improdutivas.

A pesar dessa recomendação, os países geralmente adotam uma tarifa discriminatória, aplicando tarifas menores para bens de capital e bens intermediários em relação às de bens de consumo. 0 Chile é uma exceção, praticando uma tarifa uniforme. ${ }^{9}$

N os G ráficos 2 e 3 são apresentados, respectivamente, os desvios, em pontos de percentagem, das tarifas nominal e ef etiva em relação à média geral (exclusive a indústria automotiva), no M ERCOSUL.

Inicialmente, duas observações merecem destaque. Primeiro, constata-se a disparidade do grau de proteção nominal e efetiva usufruída pelo setor automotivo. No entanto, o acordo preliminar alcançado para a elaboração do regime automotriz no M ER CO SU L revela que dificilmente os governos terão interesse, a médio prazo, em reduzir a proteção desse setor. Segundo, o grau de proteção efetiva de bens de capital, motivo de intensa controvérsia recente, não é tão elevado em relação à média. 0 setor de máquinas e tratores está bem próximo da média, enquanto material elétrico, ainda que desfrute de uma posição favorável, encontra-se em sétimo lugar por ordem decrescente.

A dicionalmente, nota-se que as atividades cuja competitividade externa é determinada pela dotação de recursos naturais, tais como petróleo e carvão, extrativa mineral, agropecuária e refino de petróleo, desfrutam de um grau de proteção efetiva bastante inferior à média.

${ }^{9}$ A tualmente de $9 \%$, à exceção de três produtos agrícolas e automóveis. 
Gráfico 2

Desvios das tarifas nominais extemas do Mercosul em relação à média geral* (pontos de percentagem)

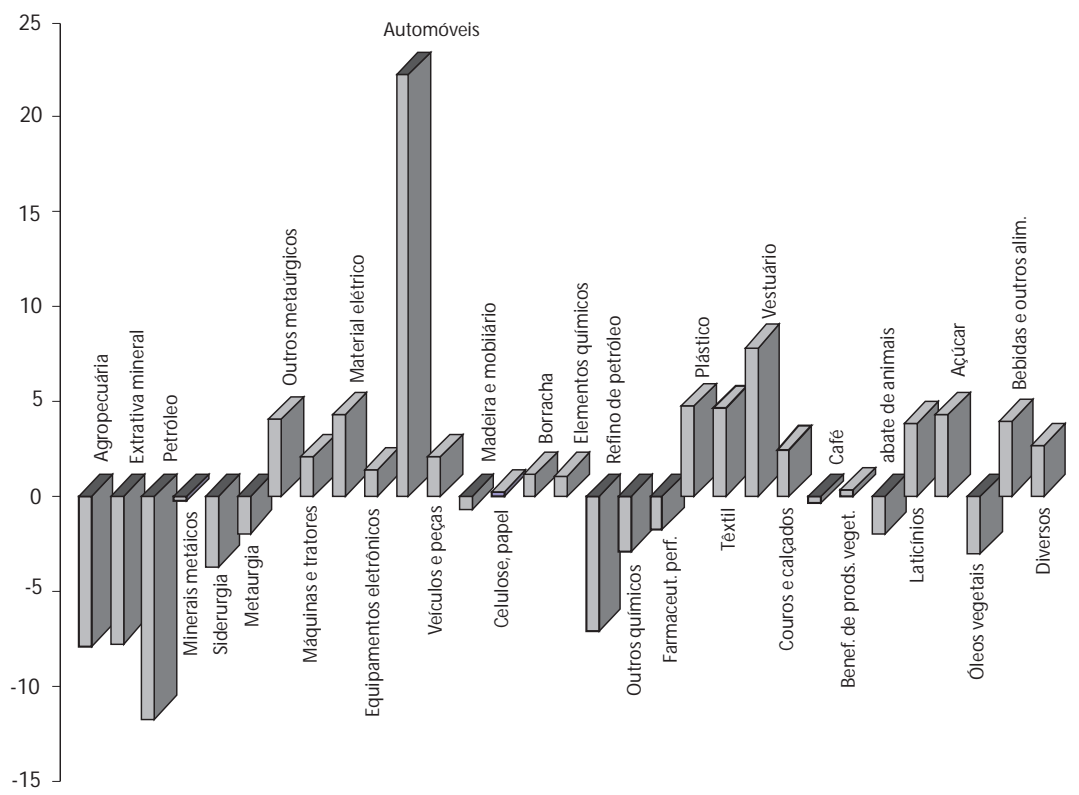

*A tarifa média geral exclui automóveis. Fonte: elaboração própria.

Gráfico 3

Desvios das tarifas efetivas do Mercosul em relação à média geral* (pontos de percentagem)

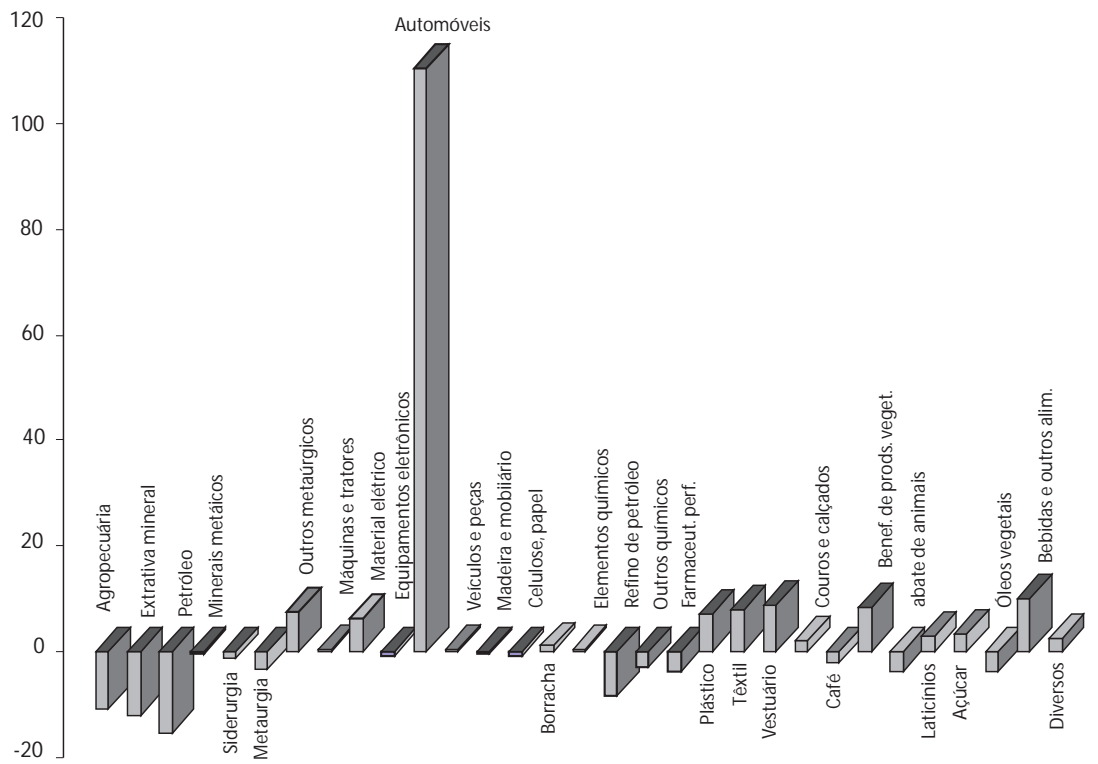

*A tarifa efetiva média geral exclui automóveis. Fonte: elaboração própria. 
Entre as opções de mudanças nas tarifas relativas de bens de capital, mantida a tarifa nominal média de $12 \%$, dificilmente haveria condições políticas para implementar uma tarifa uniforme, pois isto requereria uma redução nos graus de proteção nominal de bens de consumo e um aumento no de bens intermediários. Isso causaria uma forte realocação de recursos, a qual, ainda que adequada a Iongo prazo, provocaria custos de ajustamento substanciais a curto e médio prazos.

U ma política alternativa seria aplicar o método "concertina" (C orden, 1997), em várias etapas. Segundo essa abordagem, em cada período seriam reduzidas todas as tarifas nominais superiores a um percentual fixado arbitrariamente. Por exemplo, num primeiro momento, as tarifas nominais acima da média seriam reduzidas até atingir esse valor. $\mathrm{N}$ um segundo momento, uma nova tarifa nominal média seria calculada e repetido o procedimento anterior e assim sucessivamente. 0 ponto final alcançado seria uma determinada tarifa efetiva com baixa dispersão. $\mathrm{N} o$ entanto, os setores com tarifas inferiores à média final teriam suas alíquotas mantidas, durante todo o processo.

$N$ esse caso, as dificuldades estariam concentradas na escolha da tarifa média final para a qual deveriam convergir todas as tarifas superiores a esse nível e o número de etapas que seriam cumpridas.

Evidentemente, a atual tarifa média poderia ser mantida, reduzindo-se gradualmente apenas as tarifas superiores a ela, o que conduz a uma maior uniformidade na estrutura tarifária.

Finalmente, no caso provável de ser mantida uma estrutura tarifária diferenciada, um estudo mais aprofundado sobre a adequação das tarifas de bens de capital deveria ser realizado. Certamente, uma proposta radical de tarifa nula não é apropriada, até porque os grandes países produtores e exportadores de bens de capital não têm tarifa zero. Esses mesmos países grandes são também importadores, o que sugere uma indução ao comércio intra-indústria. Dado que o nível tarifário atual de bens de capital no M ERCOSUL pode ser considerado prejudicial ao estímulo de investimentos e à competitividade externa, uma alternativa interessante poderia ser a combinação de uma tarifa menos el evada com um subsídio à produção doméstica.

\section{UNIÃO ADUANEIRA VERSUSÁREA DE LIVRE-COM ÉRCIO}

\subsection{As mudanças na tarifa externa comum}

A aprovação de uma tarifa externa comum, com as exceções conhecidas e um cronograma de redução gradativa até a uniformização, deveria ser suficiente para impedir que interesses locais pressionassem os governos domésticos, em busca da adoção de medidas protecionistas (Corden, 1995). Entretanto, no caso do M ER COSUL, os países-membros têm, por vezes, anunciado alterações na tarifa externa comum, buscando posteriormente a aprovação de seus parceiros ${ }^{10}$.

\footnotetext{
${ }^{10}$ A Igumas vezes as medidas adotadas afetaram tanto as importações provenientes dos países-membros como as de terceiros países.
} 
A A rgentina tomou a primeira iniciativa, em fevereiro de 1995, aplicando novamente ${ }^{11}$ uma taxa de estatística de 3\% nas importações extra-M ER CO SUL. Essa medida não tinha fins protecionistas e buscava gerar uma receita tributária adicional que permitisse o equilíbrio fiscal, fundamental para a continuidade do Programa de Conversibilidade, afetado negativamente pela crise mexicana no final de 1994.

0 governo brasileiro, preocupado com as projeções para o déficit na balança comercial feitas no início de 1995, elevou, em março daquele ano, as tarifas de 109 bens de consumo duráveis, tais como automóveis, televisores, radiogravadores e toca-discos a laser. A demais, com o intuito de pressionar os preços domésticos, solicitou e obteve o apoio dos demais países do bloco para a inclusão de mais 150 produtos na Lista de Exceção $\mathrm{N}$ acional. Deste total, 61 poderiam ser revisados e substituídos a cada três meses, ficando os restantes sujeitos a uma revisão anual (K ume, 1998).

O Paraguai também procurou manter 0 acesso a importações de matériasprimas no mercado internacional sem o pagamento da tarifa externa comum. Em conseqüência, decidiu-se permitir a importação pelos países sócios de até 50 produtos sem o pagamento da tarifa externa comum, nos casos de insuficiência de oferta regional e sob a aprovação da Comissão de Comércio do M ERCOSUL.

Em setembro de 1997, em decorrência da menor disponibilidade dos fluxos de capitais externos provocada pela crise asiática, o governo brasileiro aumentou temporariamente as tarifas em três pontos de percentagem, com o intuito de reduzir as importações.

Em março de 2001, o governo argentino, com o objetivo de estimular o crescimento econômico, reduziu as tarifas de bens de capital de $14 \%$ para $0 \%$ e aumentou as de bens de consumo de $20 \%$ para $35 \%$. A livre entrada de máquinas e equipamentos provenientes de terceiros países, fora do bloco regional, provocou fortes reações do governo brasileiro, em decorrência da perda de preferência tarifária que favorecia as exportações brasileiras desses bens ao mercado argentino.

Em julho de 2001, o governo uruguaio reduziu para zero as tarifas de bens de capital e impôs uma alíquota adicional de três pontos de percentagem para as importações restantes, inclusive as provenientes do M ER COSUL. O Paraguai também elevou em 10 pontos de percentagem as tarifas de 330 produtos.

No final de 2002, a Argentina solicitou a manutenção das tarifas de $0 \%$ para bens de capital por mais um ano, sendo concedida uma prorrogação até junho de 2003. $N$ essa data, a pedido do governo argentino, o prazo foi estendido até 0 final do mesmo ano.

Em resumo, a união aduaneira imperfeita passou a funcionar como uma zona de livre-comércio. $\mathrm{N} o$ entanto, a redução das tarifas de bens de capital a zero não tem o respaldo do governo brasileiro. Sua manutenção torna inviável sustentar a tarifa externa comum, acordada no Protocolo de O uro Preto, em 1994.

${ }^{11}$ A taxa de estatística havia sido extinta com a vigência da TEC. 


\subsection{U nião aduaneira versus zona de livre-comércio: um debate}

A tarifa externa comum, cuja plena vigência estava prevista para 2006, foi 0 resultado de intensas negociações entre os governos dos países membros do M ER COSUL e representou, naquele momento, um equilíbrio "político" no balanço de modificações tarifárias aceitas pelos países, o que não implicou, necessariamente, uma distribuição eqüitativa dos benefícios e custos do livre comércio intra-regional.

As permissões temporárias concedidas às mudanças na tarifa externa comum, sempre que apoiadas em argumentos macroeconômicos, propiciaram a flexibilidade necessária à execução da política comercial, contornando a rigidez imposta pela união aduaneira.

$\mathrm{N}$ o entanto, as recentes medidas adotadas pela Argentina e pelo Uruguai para o setor de bens de capital provocaram uma alteração de proporções significativas no equilíbrio entre os custos e os benefícios que caracterizavam a união aduaneira até recentemente.

N ormalmente, essa medida deveria ser considerada temporária, como as alterações promovidas até então. Contudo, alguns segmentos dos governos e da academia nos três países vizinhos têm defendido o retrocesso do M ERCOSUL a uma zona de livre-comércio, o que Ihes permitiria uma autonomia na condução da política comercial. N esse contexto, A rgentina, Paraguai e Uruguai poderiam manter a tarifa de $0 \%$ permanentemente para máquinas e equipamentos, bem como assinar novos acordos bilaterais que minimizassem as perdas impostas pelas preferências tarifárias que beneficiam o Brasil em outros produtos manufaturados.

Para o Brasil, que, como país grande do M ER COSUL, já desfrutava de um ganho relativamente menor com a formação da união aduaneira ${ }^{12}$, sua substituição por uma área de livre-comércio implicaria perdas adicionais dos ganhos provenientes com o desvio de comércio, tornando a participação no M ER COSUL menos atraente economicamente. ${ }^{13}$

N ão obstante, a opção por uma zona de livre-comércio acarretaria outros custos, não restritos ao Brasil, na medida em que requereria um regime de regras de origem para evitar que as concessões tarifárias feitas aos países-sócios fossem apropriadas por terceiros países, através de um comércio triangular. O s controles aduaneiros necessários ao funcionamento do regime de origem poderiam impor um ônus excessivo aos exportadores, dificultando o comércio intra-regional.

Em uma área de livre-comércio, o regime de origem assume uma função preponderante e suas exigências de conteúdo regional podem servir para maximizar o desvio de comércio, principalmente por parte do país mais industrializado. Para ter acesso ao mercado de seu parceiro, sem o pagamento do imposto de im-

\footnotetext{
${ }^{12}$ Em um programa de integração econômica entre um país grande e outro pequeno, a mudança nos termos de troca será mais favorável ao país menor.

${ }^{13}$ Uma comparação entre união aduaneira e zona de livre-comércio é feita por Krueger (1995).
} 
portação, o país exportador "pequeno" deverá adquirir os insumos fabricados no país-sócio "grande". ${ }^{14}$

A princípio, as vantagens proporcionadas por um elevado nível de conteúdo regional são apropriadas apenas pelos produtores de insumos. Entretanto, em alguns setores, os produtores de bens finais também podem estar interessados em regimes de origem bastante restritivos. Esse comportamento ocorre em setores onde o custo de entrada, medido através da montagem de uma rede de fornecedores, é elevado, podendo redundar, dada a parcela de mercado conquistada, em prejuízo às novas firmas. $N$ esse caso, o regime de origem funciona como um mecanismo anticompetição e os produtores de bens finais e intermediários dividem as rendas extraordinárias conseguidas com as barreiras à entrada.

Por último, os países "pequenos" do M ERCOSUL, ao negociarem individualmente, poderão perder grande parte do poder de barganha em acordos bilaterais. Especialmente, a superposição de interesses da A rgentina e do Uruguai em eventuais acordos de livre-comércio com os Estados Unidos e a União Européia no comércio de produtos agrícolas resultaria em uma limitação no escopo de seu acesso aos mercados dos países industrializados. Ao contrário, em um acordo com o M ERCOSUL, seria possível obter maiores concessões no setor agrícola, em troca de um maior acesso de norte-americanos e europeus ao mercado brasileiro.

Em resumo, a substituição da união aduaneira por uma zona de livre-comércio pode conduzir aos seguintes problemas:

a) a transferência do debate sobre a questão da tarifa externa comum para 0 de índice de conteúdo regional, o que pode até levar a um aumento do desvio de comércio, em detrimento do país "pequeno";

b) a criação de restrições ao comércio intra-bloco, decorrentes dos custos de funcionamento do regime de origem; e

c) a perda do poder de barganha nas negociações bilaterais por parte de países menores e mais especializados na produção agrícola.

\section{CON SIDERAÇÕES FINAIS}

A análise da estrutura da tarifa efetiva no M ER COSUL indica um certo grau de dispersão que poderia ser corrigido. No entanto, dada a escalada tarifária em vigor, a adoção de uma tarifa uniforme esbarraria em grandes dificuldades políticas, na medida em que alguns setores teriam seus níveis de proteção ef etiva reduzidos, passando a enfrentar maior competição com produtos importados de terceiros países e um aumento nos custos de produção, via elevação nas tarifas de seus insumos.

Assim, uma reforma tarifária no M ERCOSUL poderia buscar uma maior

${ }^{14}$ Krueger (1993) argumenta que esse procedimento foi adotado pelos Estados Unidos nas negociações com o M éxico, no âmbito do N AFTA. 
uniformidade nos graus de proteção efetiva, aplicando-se gradualmente o método concertina.

0 nível de proteção efetiva desfrutado pelos produtores de máquinas e equipamentos não é muito distante da média e não há indícios de que a tarifa relativa de bens de capital no M ERCO SUL seja mais elevada que a aplicada por outros países em desenvolvimento. Todavia, comparada com a dos países asiáticos e das nações desenvolvidas, a tarifa de bens de capital é relativamente el evada, sugerindo a possibilidade de ef eitos negativos sobre a competitividade externa e 0 crescimento econômico.

Dessa forma, a manutenção da união aduaneira com uma redução na tarifa externa comum do M ER CO SUL poderia atender aos interesses dos países-membros que se sentem prejudicados pelos custos provocados pelo desvio de comércio em favor da produção industrial brasileira, principalmente em bens de capital. N o entanto, a fixação de uma tarifa zero para máquinas e equipamentos não encontra respaldo na experiência de outros países.

Uma zona de livre-comércio, apesar de permitir maior autonomia na condução da política comercial, substituiria as discussões sobre a fixação da tarifa externa comum pelas exigências relacionadas ao conteúdo regional a ser estabelecido para cada produto. D ependendo dos requisitos impostos pelo regime de origem, o custo do desvio de comércio poderá ser equivalente ou superior ao de uma tarifa externa comum. A lém disso, os custos de obtenção do certificado de origem poderão acrescentar mais uma barreira ao comércio intra-regional.

Finalmente, os países "pequenos" do bloco, em troca da autonomia obtida com a transformação do M ER COSUL em uma área de livre-comércio, teriam, como contrapartida, uma perda do poder de barganha nas negociações bilaterais, principalmente com os Estados Unidos e a União Européia.

\section{ANEXO}

\section{M etodologia e Procedimentos para a Estimação da Tarifa Efetiva}

\section{Conceito e fórmula de cálculo}

A fórmula de cálculo da proteção efetiva é expressa da seguinte forma: ${ }^{15}$

$g_{j}=\left(t_{j}-\sum a_{i j} \mid c t_{i}\right) /\left(1-\sum a_{i j} l c\right)$

onde:

$g_{j}=$ tarifa efetiva do produto $j$;

aij $\mathrm{l}^{\mathrm{c}}=$ a parcela do insumo i no produto $\mathrm{j}$, ambos a preços internacionais;

$\mathrm{t}_{\mathrm{j}}=$ tarifa nominal da atividade $\mathrm{j} ; \mathrm{e}$

$\mathrm{t}_{\mathrm{i}}=$ tarifa nominal do insumo $\mathrm{i}$.

${ }^{15} \mathrm{O}$ desenvolvimento algébrico desta fórmula é encontrado em Corden (1971, p. 35-38). 


\section{Procedimentos metodológicos e fontes dos dados}

a) parcela do insumo i no produto j medido a preços domésticos $\left(a_{i j} d\right)$

A M atriz de Insumo-Produto de 1996, elaborada pelo IBGE, apresenta duas formas de classificação por setores: 80 produtos e 50 atividades. Para obter os coeficientes técnicos no nível de 80 produtos, multiplicamos a M atriz B (Tabela 16, $M$ atriz de Insumo-Produto, IBGE), que mostra a participação de cada insumo adquirido no mercado interno no valor da produção de cada produto, pela $M$ atriz DE (18), que revela a distribuição setorial do produto sob a hipótese de constant market share. 0 mesmo procedimento foi adotado para os insumos adquiridos no mercado externo. A partir destes cálculos, somamos os coeficientes de cada setor:

$$
a_{i j}{ }^{d}=a_{i j}+m_{i j}
$$

onde:

$a_{i j}{ }^{d}=$ parcela total do insumo i utilizado no produto j;

$a_{i j}=$ parcela do insumo $\mathrm{i}$ adquirido no mercado interno no produto j, medido a preços domésticos; e

$m_{i j}=$ parcela do insumo $\mathrm{i}$ importado no produto $\mathrm{j}$.

b) tarifa nominal

O s dados de tarifa nominal estão disponíveis segundo a classificação da N omenclatura Comum do M ERCOSUL (N CM -SH), com cerca de 8.750 itens, sendo adotada a compatibilização entre esses itens e os produtos da $\mathrm{M}$ atriz de Insumo-Produto.

As alíquotas do imposto de importação de petróleo e seus derivados não foram consideradas neste estudo, pois os preços desses produtos têm sido controlados, até o momento, pelo governo.

c) parcela do insumo i no produto j a preços internacionais $\left(a_{i j} \mid c\right)$

As parcelas dos insumos i no produto $\mathrm{j}$ da $\mathrm{M}$ atriz de Insumo-Produto estão distorcidas pela política comercial (tarifas e barreiras não-tarifárias). As parcelas totais dos insumos i no produto j a preços internacionais foram estimadas da seguinte forma ${ }^{16}$ :

$$
a_{i}{ }^{\text {tlc }}=a_{i j}\left(1+t_{j}\right) /\left(1+t_{i}\right)+m_{i j}\left(1+t_{j}\right)
$$

onde os símbolos foram definidos anteriormente e as tarifas correspondem a 1996.

Como o valor das importações na M atriz de Insumo-Produto do IBGE é estimado a preços básicos, isto é, excluindo-se todos os tributos, inclusive o impos-

\footnotetext{
${ }^{16}$ Lembrando que $a_{i j}{ }^{1 c}=P_{i} Q_{j} / P_{j}$, onde $a_{i j}{ }^{1 c}$ é o coeficiente técnico de produção de livre-comércio, $\mathrm{Pi}$ é o preço internacional do insumo $i, Q_{i}$ a quantidade física do insumo i e $P_{j}$ o preço mundial do produto final, podemos notar que as tarifas introduzem a seguinte distorção: $a_{i j}=P_{i} Q_{i}\left(1+t_{j}\right) / P_{j}\left(1+t_{j}\right)$, onde $a_{i j}{ }^{d}$ é o coeficiente técnico de produção medido a preços domésticos. Portanto, $a_{i j}{ }^{l c}=$ $\operatorname{aij}\left(1+t_{j}\right) /\left(1+t_{i}\right)$.
} 
to de importação, a sua parcela no produto é corrigida apenas pela tarifa incidente sobre o produto $\mathrm{j}$.

d) valor adicionado

0 valor adicionado é mensurado pelo resíduo entre o preço do produto e a soma dos custos dos insumos comercializáveis. Portanto, inclui, além da remuneração aos fatores de produção primários, capital e trabalho, o custo dos insumos não-comercializáveis e a depreciação. Este conceito ampliado de valor adicionado é conhecido como método Corden, que assume implicitamente a premissa de que a oferta dos bens não-comercializáveis apresenta uma inclinação positiva e, conseqüentemente, a proteção efetiva a uma atividade afeta os seus preços da mesma forma que os rendimentos dos fatores primários.

\section{REFER ÊN CIAS BIBLIO GRÁFICAS}

BRADFORD DE LON G, J.; SUM M ERS, L. H. Equipment investment and economic growth. Q uarterly Journal of Economics, M ay 1991.

CORDEN, W. M. The theory of protection. Oxford: Clarendon Press, 1971.

. A western hemisphere free trade area: implications for Latin A merica. In: IN TER -AM E-

RICAN DEVELOPMENT BANK (IDB), ECONOMIC COM MISSION FOR LATIN AM ERI-

CA AND THE CARIBEAN (ECLAC) (eds.). Trade liberalization in the western hemisphere. Washington, D.C., 1995.

Trade policy and economic welfare. $2^{\text {nd }}$ ed. Oxford: Clarendon Press, 1997.

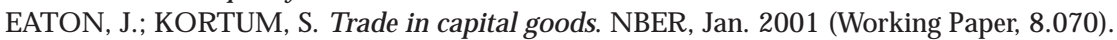

$\mathrm{H}$ SIEH , C. Coments. Trade policy and economic growth: a skeptic's guide to the cross-national evidence. In: RODRIGUEZ, F.; RODRIK, D. N BER M acroeconomics A nnual, 2000.

IBGE. Matriz de Insumo Produto do Brasil - 1996. Rio de Janeiro, 1999.

JONES, C. I. Economic growth and the relative price of capital. Journal of M onetary Economics, v. 34, 1994.

JOH N SO N , H. Tariffs and economic development: some theoretical issues. Journal of D evelopment Studies, vol. 1, n. 1, O ctober, 1964. Reimpresso em Johnson, H. A spects of the theory of tariffs. London: George Allen \& Unwin, 1971.

KRUEGER, A. O. Free trade agreements as protectionist devices: rules of origin. N BER, Apr. 1993 (Working Paper, 4.352).

. Free trade agreements versus customs unions. N BER, A pr. 1995 (Working Paper, 5.084).

KUM E, H. M ERCOSUL 1995: uma avaliação preliminar. A E conomia Brasileira em Perspectiva 1996, v. 1. Rio de Janeiro: IPEA, 1996.

KUME, J. A política de importação no Plano Real e a estrutura de proteção efetiva. A Economia Brasileira em Perspectiva - 1998, v. 1. Rio de Janeiro: IPEA, 1998.

O M C. Informe sobre el comercio mundial 2003. Genebra: O rganização M undial do Comércio, 2003.

PAN AGARIYA, A.; RODRIK, D. Political-economy arguments for a uniform tariff. N BER, M ar. 1991 (Working Paper, 3.661).

UN CTAD. Trains - trade analysis and information system. Genebra, 2000 (versão 7.0). 